\title{
Postoperative Pulmonary Complications in the Morbidly Obese: The Role of Tidal Volume and Type of Abdominal Surgery
}

\author{
Carlos E Guerra-Londono, Xiaoxia Han, and Donald H Penning
}

\begin{abstract}
BACKGROUND: The patient who is morbidly obese is not adequately represented in the evidence recommending intraoperative low tidal volume $\left(V_{T}\right)$ ventilation. We aimed to explore the association between $V_{T}$ adjusted for ideal body weight (IBW) and the occurrence of postoperative pulmonary complications in subjects who were morbidly obese and undergoing abdominal surgery, as well as its implications on intraoperative ventilatory variables. METHODS: We included 734 subjects with a body mass index of at least $40 \mathrm{~kg} / \mathrm{m}^{2}$, undergoing open or laparoscopic abdominal surgery that lasted for at least $120 \mathrm{~min}$. Clinical variables were obtained to estimate the preoperative pulmonary risk as well as intraoperative ventilator data to perform associations. Outcomes were defined by medical billing code diagnoses and oxygen use. All data were collected electronically by using Structured Query Language. RESULTS: The subjects received a mean $V_{T} / I B W$ of $9.41 \mathrm{~mL} / \mathrm{kg}$ IBW, and postoperative pulmonary complications occurred in $7.5 \%$ of the subjects. The occurrence of complications was correlated with the presence of several preoperative risk factors for postoperative pulmonary complications. $\mathrm{V}_{\mathrm{T}} / \mathrm{IBW}$ was not associated with postoperative pulmonary complications. This finding remained present after separating different levels of $V_{T} / \mathbf{I B W}$. In a multivariate analysis, only laparoscopic surgery was an independent protective factor against postoperative pulmonary complications (odds ratio $0.07,95 \%$ CI $0.01-0.55$ ). CONCLUSIONS: $V_{T} /$ IBW was not associated with the occurrence of postoperative pulmonary complications in subjects who were morbidly obese and undergoing prolonged abdominal surgery. Future prospective studies are indicated to guide the optimum ventilation strategy for patients who are morbidly obese. Key words: morbid obesity; tidal volume; pulmonary complications; surgery; laparoscopy; ventilation. [Respir Care 2020;65(12):1908-1915. (c) 2020 Daedalus Enterprises]
\end{abstract}

\section{Introduction}

In the general population, a protective lung ventilation strategy during surgery results in a decreased incidence of postoperative pulmonary complications. ${ }^{1-3}$ The combination of low tidal volume $\left(\mathrm{V}_{\mathrm{T}}\right)$ and PEEP, with or without recruitment maneuvers, has been shown to be the most

Drs Guerra-Londono and Penning are affiliated with the Department of Anesthesiology, Pain Management, and Perioperative Medicine, Henry Ford Health System, Detroit, Michigan. Dr Han is affiliated with the Department of Public Health Sciences, Henry Ford Health System, Detroit, Michigan.

Dr Guerra-Londono presented a poster of this paper at Anesthesiology 2018, held October 13-17, 2018, in San Francisco, California.

The authors declare no conflicts of interest. beneficial. ${ }^{4-6}$ In the surgical setting, studies used and defined protective $\mathrm{V}_{\mathrm{T}}$ as $5-8 \mathrm{~mL} / \mathrm{kg}$ ideal body weight (IBW), and compared it with conventional $\mathrm{V}_{\mathrm{T}}$ of $>8 \mathrm{~mL} / \mathrm{kg}$ IBW, which usually ranges between 9 and 12 $\mathrm{mL} / \mathrm{kg}$ IBW. ${ }^{1,2}$ Despite a strong level of evidence behind these interventions, it has been demonstrated that intraoperative lung-protective strategies are not uniformly used in clinical practice. ${ }^{7}$

Severe grades of obesity are poorly represented in the cumulative evidence, ${ }^{1}$ and patients who are morbidly obese

\footnotetext{
Correspondence: Carlos E Guerra-Londono MD, Department of Anesthesiology, Pain Management, and Perioperative Medicine, Henry Ford Health System, 2799 W Grand Blvd, Detroit, MI 48202. E-mail: guerra.carloseduardo@gmail.com.
}

DOI: $10.4187 /$ respcare. 07777 
are particularly prone to receive higher $\mathrm{V}_{\mathrm{T}}$ when adjusted for IBW. ${ }^{8}$ Although other components of lung protective ventilation have been evaluated in several trials, to our knowledge, a low $\mathrm{V}_{\mathrm{T}}$ strategy has never been tested in trials for this population. ${ }^{9}$ The aim of this study was to explore $\mathrm{V}_{\mathrm{T}}$ in relation to the postoperative pulmonary outcome of subjects who were morbidly obese, as well as its implications on intraoperative ventilatory settings. This was intended to be an exploratory analysis because an evidencebased recommendation for $\mathrm{V}_{\mathrm{T}}$ has not been specifically defined for this population.

\section{Methods}

\section{Study Design}

This was a retrospective single-center study at a tertiary care, university-affiliated hospital. Approval from our institutional review board was obtained before initiation of the study, and it was considered exempt from the need of informed consent.

\section{Inclusion and Exclusion Criteria}

We selected open or laparoscopic abdominal-pelvic procedures that lasted at least $120 \mathrm{~min}$ (from induction to extubation). We included adult subjects (ages $\geq 18 \mathrm{y}$ ) with a body mass index (BMI) of at least $40 \mathrm{~kg} / \mathrm{m}^{2}$ who were admitted for postoperative care, intubated after induction, and extubated at the end of the procedure. Cardiac, thoracic, vascular, head and neck, neurosurgical, and other nonabdominal procedures were excluded. Our selection criteria assumed that protective strategies might have differential effects in nonabdominal surgery ${ }^{10}$ and that pulmonary outcomes should be addressed separately for cardiothoracic procedures. We also excluded cesarean sections and gynecologic procedures that did not require laparoscopy or an abdominal or pelvic skin incision (eg, dilation and curettage). Records that lacked information with regard to height and weight, an electronic anesthesia record, or preoperative $\mathrm{S}_{\mathrm{pO}_{2}}$ were also excluded.

\section{Variables}

Preoperative Variables. We obtained demographics, which included age, sex, weight, and height. We also obtained the clinical variables that were relevant to estimate the preoperative risk of postoperative pulmonary complications based on the risk factors outlined by the ARISCAT (Assess Respiratory Risk in Surgical Patients in Catalonia) score, ${ }^{11}$ a well-known and externally validated risk score. ${ }^{12}$ This included the American Society of Anesthesiologists physical status, a system with 6 classes that reflect progressive increases in preoperative morbidity. ${ }^{13}$ We also

\section{QUICK LOOK}

\section{Current knowledge}

In the general population, intraoperative protective ventilation with low tidal volumes is currently recommended. Nonetheless, patients who are morbidly obese are more likely to receive high tidal volumes, which has not been linked in observational studies to more complications in this population.

\section{What this paper contributes to our knowledge}

In this retrospective study, low tidal volume was not associated with clinical postoperative pulmonary complications. In turn, laparoscopic surgery (as opposed to open surgery) was independently correlated with decreased pulmonary complications.

collected the history of COPD, asthma, laparoscopic and/or open surgery, liver cirrhosis, and congestive heart failure because these are known risk factors not included in the score. ${ }^{14,15}$

Intraoperative Variables. Data were derived from the anesthesia information management system, which was implemented in January 2015. In our institution, an electronic anesthesia record is generated with prospectively collected information transmitted from the anesthesia machine and monitor. Other data that required manual input from the provider include the anesthetic events (induction, intubation, emergence, extubation, recruitment maneuvers) as well as medications administered, which can also be recorded in real time with 1-min intervals. We collected expiratory $\mathrm{V}_{\mathrm{T}}$, mode of ventilation, PEEP, breathing frequency, peak inspiratory pressure (PIP), and end-tidal carbon dioxide $\left(\mathrm{P}_{\mathrm{ETCO}_{2}}\right)$ levels for our analysis.

\section{Data Collection}

The Department of Quality and Clinical Analytics performed an electronic search of the data by using Structured Query Language of the electronic medical records. No data were collected manually, but the data set was examined after collection to ensure that the inclusion and exclusion criteria were met.

\section{Outcomes}

We collected respiratory outcomes at $30 \mathrm{~d}$ after surgery. These included new diagnoses of pneumonia (including aspiration pneumonitis), atelectasis, bronchitis or exacerbation of COPD or asthma, mild respiratory failure (defined 
as the need of supplementary oxygen starting $12 \mathrm{~h}$ after surgery until $5 \mathrm{~d}$ after surgery), severe respiratory failure (a diagnosis of acute respiratory failure by International Classification of Diseases code or a need of intubation), and pleural effusion. As with the preoperative clinical history, most of the postoperative outcomes (except oxygen use and intubation) were collected by using the presence of ICD-10 that matched these events. The presence of these diagnoses determined the occurrence of an event or postoperative pulmonary complication. Because the oldest portion of the sample may have included ICD-9, the entire sample was also queried for the corresponding ICD-9 and these were included in the outcomes. Our primary outcome was the proportion of the subjects who experienced any postoperative pulmonary complications at $30 \mathrm{~d}$.

\section{Statistical Analysis}

The subjects were stratified into 2 groups based on whether they experienced postoperative pulmonary complications. IBW was calculated by using the following for$\operatorname{mula}^{16}$ : IBW for men $(\mathrm{kg})=50+2.3$ (height $[\mathrm{in}]-60$ ), and IBW for women $(\mathrm{kg})=45.5+2.3$ (height $[\mathrm{in}]-60$ ). The baseline characteristics, preoperative risk factors, and intraoperative ventilator data were summarized with mean, $\mathrm{SD}$, or median and interquartile range for continuous variables, and frequency and proportion for categorical variables. The subjects were divided into 2 groups by whether they experienced postoperative pulmonary complications. The 2 groups were compared with the independent $t$ test or the Wilcoxon rank-sum test for continuous variables, and the chi-square test or Fisher exact test if any cell with an expected frequency $<5$ for categorical variables. For our secondary analysis, we explored the relationship between $\mathrm{V}_{\mathrm{T}} / \mathrm{IBW}$ ratio and PIP, $\mathrm{P}_{\mathrm{ETCO}_{2}}$, PEEP, and minute ventilation by using Pearson correlations. Scatterplots were used to visualize data. All statistical analyses were performed by using R software (version 3.6, R Foundation for Statistical Computing, Vienna, Austria). All statistical tests were 2 -sided, and $P<.05$ was considered statistically significant.

The intraoperative ventilator data were filtered to exclude any data point outside of the time interval between intubation and extubation as well as modes of ventilation considered to be primarily spontaneous or not controlled by the anesthesia machine (eg, spontaneous, manual, pressure support, and CPAP). An examination of the data points of synchronized intermittent mandatory ventilation modes revealed that these values did not affect the average or the distribution of the data, for which they were included as part of the mean. For $\mathrm{V}_{\mathrm{T}}$, blank data points and data points with no specification of a ventilation mode were also excluded from the analysis. To adjust for erroneous data, the following were the ranges for inclusion of the intraoperative data points: $\mathrm{V}_{\mathrm{T}}$ between 4 and $15 \mathrm{~mL} / \mathrm{kg}$ IBW, PEEP between 0 and $20 \mathrm{~cm} \mathrm{H}_{2} \mathrm{O}$, PIP between 10 and $60 \mathrm{~cm}$ $\mathrm{H}_{2} \mathrm{O}, \mathrm{P}_{\mathrm{ETCO}_{2}}$ between 20 and $60 \mathrm{~mm} \mathrm{Hg}$, and breathing frequency of 6-22 breaths/min. We then calculated the mean for every one of the variables.

\section{Results}

We identified, through the electronic search, 961 records of surgeries performed between January 2015 and March 2018. We examined these records and eliminated those erroneously identified as abdominal (eg, endovascular procedures) as well as those records that lacked preoperative $\mathrm{S}_{\mathrm{PO}_{2}}$ values. A total of 734 surgeries were included in our final sample. The baseline clinical characteristics of our study sample are described in Table 1. In brief, most of the procedures were performed in women $(79.6 \%)$ and were laparoscopic in nature $(77.2 \%)$. Certain conditions were prevalent in the subjects who were morbidly obese, including obstructive sleep apnea (52.5\%), asthma (24.1\%), and recent acute respiratory infection (43.7\%). The most common American Society of Anesthesiologists class recorded was $3(87.3 \%)$.

The intraoperative ventilator variables are shown in Table 2. The IBW was mean \pm SD $58.77 \pm 10.28 \mathrm{~kg}$, and surgeries lasted a mean $\pm \mathrm{SD}$ of $184.99 \pm 66.04 \mathrm{~min}$. Importantly, the average PEEP was $5 \mathrm{~cm} \mathrm{H}_{2} \mathrm{O}$, with a minimum SD of 0.82. The mean \pm SD $V_{T}$ was $543 \pm 67.74$ $\mathrm{mL}$, for a $\mathrm{V}_{\mathrm{T}} / \mathrm{IBW}$ of $9.41 \pm 1.4 \mathrm{~mL} / \mathrm{kg}$ IBW. Of $734 \mathrm{sub}-$ jects, $131(17.8 \%)$ received a $\mathrm{V}_{\mathrm{T}}<8 \mathrm{~mL} / \mathrm{kg}$ IBW, 357 (48.6\%) received a $\mathrm{V}_{\mathrm{T}}$ of $8-10 \mathrm{~mL} / \mathrm{kg} \mathrm{IBW}$, and 246 (33.5\%) received a $\mathrm{V}_{\mathrm{T}}>10 \mathrm{~mL} / \mathrm{kg}$ IBW.

There were 96 postoperative pulmonary complications in our sample. The most common complication was mild respiratory failure (ie, postoperative supplementary oxygen), which occurred in 46 subjects, followed by severe respiratory failure (21 subjects). Only one subject required reintubation. Other complications recorded were aspiration pneumonitis (6 subjects), atelectasis ( 3 subjects), pneumonia (7 subjects), bronchitis (6 subjects), and pleural effusion (6 subjects). Overall, 55 of 734 subjects (7.5\%) had at least one postoperative pulmonary complication. In the subjects who received $<8,8-10$, and $>10 \mathrm{~mL} / \mathrm{kg} \mathrm{IBW}$, the rates of complications were 4.58 (6/131), 9.17 (30/357), and 8.37\% (19/227), respectively.

The subjects who experienced pulmonary complications were older $(55.42$ vs 47.63 y; $P<.001)$, had more American Society of Anesthesiologists class 4 (20.1 vs $1.6 \% ; P<.001$ ), underwent an emergency (30.9 vs 5.2\%; $P<.001$ ), and open abdominal procedures (56.4 vs $20 \%$; $P<.001)$ more frequently, and had a longer duration of surgery (227.95 vs $181.51 \mathrm{~min} ; P=.002$ ). In addition, these subjects had a higher prevalence of congestive heart 
Table 1. Baseline Clinical Characteristics Among Subjects Who Were Morbidly Obese and Undergoing Abdominal Surgery in Relation With Postoperative Pulmonary Complications

\begin{tabular}{|c|c|c|c|c|}
\hline Variable & $\begin{array}{l}\text { All Subjects } \\
(N=734)\end{array}$ & $\begin{array}{c}\text { Yes } \\
(n=55)\end{array}$ & $\begin{array}{c}\text { No } \\
(n=679)\end{array}$ & $P$ \\
\hline \multicolumn{5}{|l|}{ Age } \\
\hline$\leq 50 \mathrm{y}$ & $419(57.1)$ & $21(38.2)$ & $398(58.6)$ & \multirow[t]{3}{*}{.001} \\
\hline $51-80 \mathrm{y}$ & $314(42.8)$ & $33(60)$ & $281(41.4)$ & \\
\hline$>80 \mathrm{y}$ & $1(0.1)$ & $1(1.8)$ & $0(0)$ & \\
\hline \multicolumn{5}{|l|}{ Race } \\
\hline White & $309(42.1)$ & $22(40)$ & $287(42.3)$ & \multirow[t]{3}{*}{.66} \\
\hline Black & $80(10.9)$ & $8(14.5)$ & $72(10.6)$ & \\
\hline Others & $345(47)$ & $25(45.5)$ & $320(47.1)$ & \\
\hline \multicolumn{5}{|l|}{ Sex } \\
\hline Women & $584(79.6)$ & $44(80)$ & $540(79.5)$ & \multirow[t]{2}{*}{$>.99$} \\
\hline Men & $150(20.4)$ & $11(20)$ & $139(20.5)$ & \\
\hline \multicolumn{5}{|c|}{$\begin{array}{l}\text { American Society of } \\
\text { Anesthesiologists } \\
\text { physical status class }\end{array}$} \\
\hline 2 & $69(9.4)$ & $0(0)$ & $69(1.2)$ & \multirow[t]{4}{*}{$<.001$} \\
\hline 3 & $641(87.3)$ & $42(76.4)$ & $599(88.2)$ & \\
\hline 4 & $22(3)$ & $11(20)$ & $11(1.6)$ & \\
\hline 5 & $2(.3)$ & $2(3.6)$ & $0(0)$ & \\
\hline \multicolumn{5}{|c|}{ Emergency surgery } \\
\hline No & $682(92.9)$ & $38(69.1)$ & $644(94.8)$ & \multirow[t]{2}{*}{$<.001$} \\
\hline Yes & $52(7.1)$ & $17(30.9)$ & $35(5.2)$ & \\
\hline \multicolumn{5}{|c|}{ Laparoscopic surgery } \\
\hline No & $167(22.8)$ & $31(56.4)$ & $136(20)$ & \multirow[t]{2}{*}{$<.001$} \\
\hline Yes & $567(77.2)$ & $24(43.6)$ & $543(80)$ & \\
\hline \multicolumn{5}{|l|}{$\begin{array}{l}\text { Acute respiratory } \\
\text { infection }\end{array}$} \\
\hline No & $413(56.3)$ & $26(47.3)$ & $387(57)$ & \multirow[t]{2}{*}{.21} \\
\hline Yes & $321(43.7)$ & $29(52.7)$ & $292(43)$ & \\
\hline \multicolumn{5}{|c|}{$\begin{array}{l}\text { History of obstructive } \\
\text { sleep apnea }\end{array}$} \\
\hline No & $349(47.5)$ & $27(49.1)$ & $322(47.4)$ & \multirow[t]{2}{*}{.92} \\
\hline Yes & $385(52.5)$ & $28(50.9)$ & $357(52.6)$ & \\
\hline \multicolumn{5}{|c|}{$\begin{array}{l}\text { History of congestive } \\
\text { heart failure }\end{array}$} \\
\hline No & $681(92.8)$ & $42(76.4)$ & $639(94.1)$ & \multirow[t]{2}{*}{$<.001$} \\
\hline Yes & $53(7.2)$ & 13 (23.6) & $40(5.9)$ & \\
\hline \multicolumn{5}{|l|}{ History of asthma } \\
\hline No & $557(75.9)$ & $43(78.2)$ & $514(75.7)$ & \multirow[t]{2}{*}{.80} \\
\hline Yes & $177(24.1)$ & $12(21.8)$ & $165(24.3)$ & \\
\hline \multicolumn{5}{|c|}{ History of cirrhosis } \\
\hline No & $721(98.2)$ & $53(96.4)$ & $668(98.4)$ & \multirow[t]{2}{*}{.25} \\
\hline Yes & $13(1.8)$ & $2(3.6)$ & $11(1.6)$ & \\
\hline \multicolumn{5}{|l|}{ History of COPD } \\
\hline No & $680(92.6)$ & $44(80)$ & $636(93.7)$ & \multirow[t]{2}{*}{.001} \\
\hline Yes & $54(7.4)$ & $11(20)$ & $43(6.3)$ & \\
\hline
\end{tabular}

failure (23.6 vs $5.9 \% ; P<.001)$, and COPD (20 vs 6.3\%; $P=.001)$. As expected, the subjects who experienced complications had a higher prevalence of these risk factors of postoperative pulmonary complications.
There were no significant differences in the intraoperative ventilatory variables between subjects who experienced postoperative pulmonary complications and those who did not. We also explored the association between peak pressure and pulmonary complications reported in the LAS VEGAS study ${ }^{17,18}$ as well as the modified driving pressure because it has been suggested as a risk factor for severe complications (ie, intubation). ${ }^{19}$ Again, there was no significant difference between peak pressures, modified driving pressures, and the occurrence of complications.

Overall, in univariate logistic regression analysis (Tables 1 and 2), several variables were associated with the occurrence of postoperative pulmonary complications: older age, higher American Society of Anesthesiologists Classification, emergency surgery, non-laparoscopic surgery, longer duration of surgery, history of congestive heart failure, and history of COPD. Neither $\mathrm{V}_{\mathrm{T}}$ nor $\mathrm{V}_{\mathrm{T}} / \mathrm{IBW}$ were associated with the occurrence of postoperative pulmonary complications.

We then studied $\mathrm{V}_{\mathrm{T}}$ along with the other variables in a multivariate logistic regression analysis (Table 3 ). Importantly, $\mathrm{V}_{\mathrm{T}}$ was not associated with the occurrence of pulmonary complications in our study (odds ratio 1.79, 95\% CI 0.83-3.86; $P=.14$ ). We then performed a separate analysis of the rate of postoperative pulmonary complications by using several cutoffs of $\mathrm{V}_{\mathrm{T}} / \mathrm{IBW}$. There was no significant difference in the rates of complications when using $8 \mathrm{~mL} / \mathrm{kg}$ IBW as a cutoff ( 4.58 vs $8.12 \% ; P=.23)$. The subjects were also subdivided into 3 groups: $<8,8-10$, and $>10 \mathrm{~mL} / \mathrm{kg}$ IBW. Neither of these categories were statistically different in their rates of postoperative pulmonary complications (4.58 vs 9.17 vs $8.37 \% ; P=.36$ ). Notably, laparoscopic surgery remained as the sole independent protective factor against these pulmonary complications (odds ratio $0.07,95 \%$ CI $0.01-0.55$ ).

Also, we generated scatterplots with $\mathrm{V}_{\mathrm{T}}$ or $\mathrm{V}_{\mathrm{T}} / \mathrm{IBW}$ in relation to PIP, PEEP, modified driving pressure (PIP PEEP), and $\mathrm{P}_{\mathrm{ETCO}_{2}}$ (Fig. 1). Correlation coefficients are depicted in Table 4. Overall, there was poor correlation between the ventilatory variables. Nonetheless, the use of $\mathrm{V}_{\mathrm{T}} / \mathrm{IBW}$ instead of $\mathrm{V}_{\mathrm{T}}$ produced more significant findings, especially with regard to $\mathrm{P}_{\mathrm{ETCO}_{2}}$, in which $\mathrm{V}_{\mathrm{T}} / \mathrm{IBW}$ had a better correlation ( $\mathrm{r}-0.363,95 \% \mathrm{CI}-0.424$ to $-0.298 ; P<$ $.001)$.

\section{Discussion}

In the subjects who were morbidly obese and undergoing abdominal surgery, $\mathrm{V}_{\mathrm{T}} / \mathrm{IBW}$ was not associated with the occurrence of postoperative pulmonary complications, even after $\mathrm{V}_{\mathrm{T}} / \mathrm{IBW}$ was studied in several subgroups to reflect the usage of protective $(<8 \mathrm{~mL} / \mathrm{kg}$ IBW) or nonprotective ventilation $(\geq 8 \mathrm{~mL} / \mathrm{kg} \mathrm{IBW})$ in the intraoperative period. These results were in line with previous 


\section{Postoperative PUlmonary Complications AND OBesity}

Table 2. Intraoperative Ventilatory Variables Among Subjects Who Were Morbidly Obese and Were Undergoing Abdominal Surgery: Relation With Postoperative Pulmonary Complications

\begin{tabular}{|c|c|c|c|c|}
\hline Variable & All Subjects $(N=734)$ & Yes $(n=55)$ & No $(n=679)$ & $P$ \\
\hline IBW, $\mathrm{kg}$ & $58.77 \pm 10.28$ & $57 \pm 1.1$ & $58.91 \pm 10.29$ & .15 \\
\hline BMI, $\mathrm{kg} / \mathrm{m}^{2}$ & $47.7 \pm 6.66$ & $49.73 \pm 8.96$ & $47.53 \pm 6.42$ & .08 \\
\hline Duration of surgery, min & $184.99 \pm 66.04$ & $227.95 \pm 107.16$ & $181.51 \pm 60.32$ & .002 \\
\hline $\mathrm{V}_{\mathrm{T}}, \mathrm{mL}$ & $543.02 \pm 67.74$ & $535 \pm 6.1$ & $543.66 \pm 68.32$ & .24 \\
\hline $\mathrm{V}_{\mathrm{T}} / \mathrm{IBW}, \mathrm{mL} / \mathrm{kg}$ & $9.41 \pm 1.4$ & $9.53 \pm 1.11$ & $9.4 \pm 1.43$ & .37 \\
\hline Age, y & $48.21 \pm 11.8$ & $55.42 \pm 11.5$ & $47.63 \pm 11.63$ & $<.001$ \\
\hline PEEP, $\mathrm{cm} \mathrm{H} \mathrm{H}_{2} \mathrm{O}$ & $5 \pm 0.82$ & $5.18 \pm 0.95$ & $4.98 \pm 0.81$ & .20 \\
\hline $\mathrm{PIP}, \mathrm{cm} \mathrm{H} \mathrm{H}_{2} \mathrm{O}$ & $29.24 \pm 4.19$ & $28.74 \pm 3.98$ & $29.28 \pm 4.21$ & .34 \\
\hline Modified driving pressure, $\mathrm{cm} \mathrm{H}_{2} \mathrm{O}$ & $24.24 \pm 4.27$ & $23.56 \pm 4.1$ & $24.3 \pm 4.28$ & .21 \\
\hline $\mathrm{S}_{\mathrm{pO}_{2}}, \%$ & $98.86 \pm 1.18$ & $98.97 \pm 1.17$ & $98.85 \pm 1.18$ & .35 \\
\hline Preoperative $\mathrm{S}_{\mathrm{pO}_{2}}, \%$ & $98.62 \pm 3.04$ & $99.23 \pm 1.37$ & $98.5 \pm 3.26$ & .66 \\
\hline $\mathrm{P}_{\mathrm{ETCO}_{2}}, \mathrm{~mm} \mathrm{Hg}$ & $34.75 \pm 2.77$ & $34.55 \pm 2.61$ & $34.77 \pm 2.79$ & .69 \\
\hline $\mathrm{F}_{\mathrm{IO}_{2}}, \%$ & $0.79 \pm 0.16$ & $0.82 \pm 0.16$ & $0.79 \pm 0.16$ & .13 \\
\hline Breathing frequency, breaths/min & $13.1 \pm 1.83$ & $13.35 \pm 2.07$ & $13.08 \pm 1.8$ & .40 \\
\hline
\end{tabular}

$\overline{\text { Data are mean } \pm \mathrm{SD}} ; \mathrm{IBW}=$ ideal body weight; $\mathrm{BMI}=$ body mass index $; \mathrm{V}_{\mathrm{T}}=$ tidal volume; $\mathrm{PIP}=$ peak inspiratory pressure; $\mathrm{P}_{\mathrm{ETCO}_{2}}=$ end-tidal carbon dioxide

Table 3. Multivariate Logistic Regression Model Between Preoperative and Intraoperative Variables and the Occurrence of Postoperative Pulmonary Complications

\begin{tabular}{|c|c|c|}
\hline Variable & Odds Ratio $(95 \% \mathrm{CI})$ & $P$ \\
\hline $\mathrm{V}_{\mathrm{T}} / \mathrm{IBW}$ & $1.79(0.83-3.86)$ & .14 \\
\hline Age $>50$ y $($ vs $<50$ y $)$ & $3.37(0.54-21.21)$ & .20 \\
\hline Men (vs women) & $1.76(0.2-15.76)$ & .61 \\
\hline Emergent surgery & $1.27(0.06-25.68)$ & .88 \\
\hline \multicolumn{3}{|l|}{$\begin{array}{l}\text { American Society of } \\
\text { Anesthesiologists class }\end{array}$} \\
\hline 3 & $0.35(0.01-9.27)$ & .53 \\
\hline 4 & $5.94(0.12-291.07)$ & .37 \\
\hline 5 & $1.82(0.03-97.78)$ & .77 \\
\hline Acute respiratory infection & $2.6(0.38-17.72)$ & .33 \\
\hline \multicolumn{3}{|l|}{ History of } \\
\hline OSA & $1(0.17-5.93)$ & $>.99$ \\
\hline COPD & $2.35(0.21-26.56)$ & 49 \\
\hline Asthma & $0.61(0.08-4.92)$ & .65 \\
\hline Cirrhosis & $0.86(0.01-66.57)$ & .95 \\
\hline Congestive heart failure & $6.99(0.61-80.49)$ & .12 \\
\hline Duration of surgery & $1.01(1-1.02)$ & .11 \\
\hline $\begin{array}{l}\text { Laparoscopic surgery } \\
\text { (vs open surgery) }\end{array}$ & $0.07(0.01-0.55)$ & .01 \\
\hline \multicolumn{3}{|l|}{$\mathrm{S}_{\mathrm{pO}_{2}}$} \\
\hline Intraoperative & $1.11(0.48-2.59)$ & .81 \\
\hline Preoperative & $0.97(0.73-1.29)$ & .81 \\
\hline PIP & $0.95(0.66-1.37)$ & .79 \\
\hline Modified driving pressure & $1.04(0.73-1.49)$ & .82 \\
\hline $\begin{array}{l}\mathrm{V}_{\mathrm{T}}=\text { tidal volume } \\
\mathrm{IBW}=\text { ideal body weight } \\
\text { OSA = obstructive sleep apnea } \\
\text { PIP = peak inspiratory pressure }\end{array}$ & & \\
\hline
\end{tabular}

observational data for individuals who were not obese and individuals who were obese $\left(\mathrm{BMI}>30 \mathrm{~kg} / \mathrm{m}^{2}\right)$, in which $\mathrm{V}_{\mathrm{T}}$ was not an independent predictor of pulmonary complications. ${ }^{17,18}$

The average $\mathrm{V}_{\mathrm{T}}$ /IBW used in our population was 9.41 $\mathrm{mL} / \mathrm{kg}$ IBW, which showed that protective ventilation strategies are not being routinely followed in this population, even though BMI is an independent predictor of pulmonary complications ${ }^{20}$ and obstructive sleep apnea is more prevalent in patients who are morbidly obese. ${ }^{21}$ There was no significant difference in $\mathrm{V}_{\mathrm{T}} / \mathrm{IBW}$ between the subjects who did versus those who did not develop complications ( 9.5 vs $9.4 ; P=.37$ ), as has been previously reported in the general ${ }^{18}$ and in high-risk populations. ${ }^{14}$ Although the $\mathrm{V}_{\mathrm{T}}$ used in our sample was higher, the results were in line with the idea that higher BMIs are associated with higher $\mathrm{V}_{\mathrm{T}}$ either as an effect of $\mathrm{BMI}^{8,17}$ per se or because of the discrepancies between actual and IBW. ${ }^{7}$

It is notable that there was minimum variability in the levels of PEEP used in these subjects, most of them who received only $5 \mathrm{~cm} \mathrm{H}_{2} \mathrm{O}$. Several studies, which used physiologic and radiologic outcomes, support the use of higher levels of PEEP in this population..$^{9,22-24}$ Nonetheless, the PROBESE trial showed that a higher PEEP strategy did not improve clinical outcomes among patients who are obese. ${ }^{25}$ The most significant finding among the ventilatory parameters was that $\mathrm{V}_{\mathrm{T}} / \mathrm{IBW}$ was significantly better correlated to $\mathrm{P}_{\mathrm{ETCO}_{2}}$ than to $\mathrm{V}_{\mathrm{T}}$ alone.

Although several risk factors were identified in the univariate analysis, including older age, American Society of 

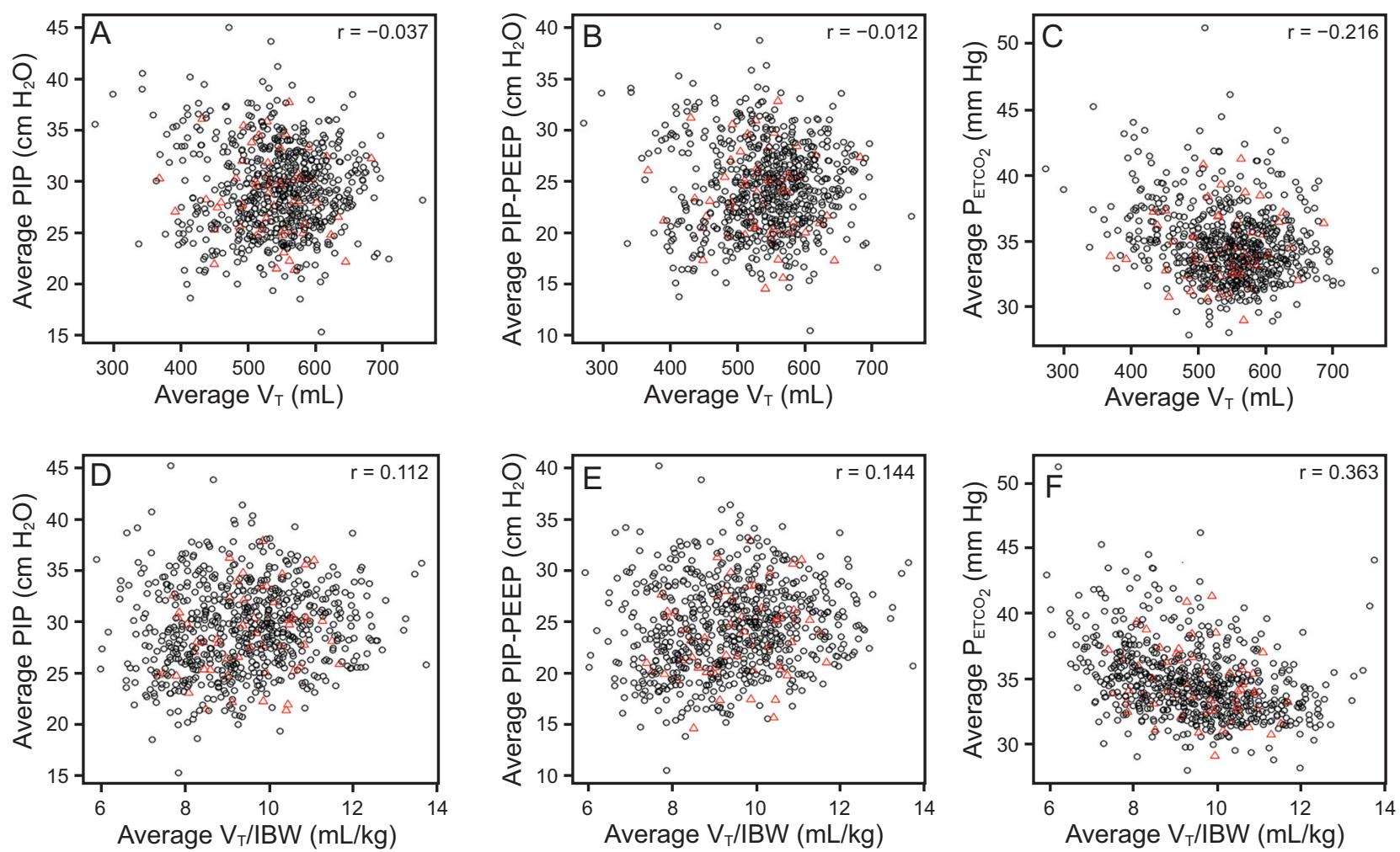

Fig. 1. Relationship between $V_{T}$ and other intraoperative ventilatory variables. $A: V_{T}$ versus PIP. $B: V_{T}$ versus modified driving pressure (PIP PEEP). C: $V_{T}$ versus $P_{E T C O}$. D: $V_{T} / I B W$ versus PIP. E: $V_{T} / I B W$ versus modified driving pressure $(P I P-P E E P)$. F: $V_{T} / I B W$ versus $P_{E T C O}$. Red triangles indicate the values at which postoperative pulmonary complications occurred. $\mathrm{V}_{\mathrm{T}}=$ tidal volume; PIP $=$ peak inspiratory pressure; $\mathrm{P}_{\mathrm{ETCO}_{2}}=$ end-tidal carbon dioxide; IBW = ideal body weight.

Table 4. Pearson Correlation Among Intraoperative Ventilation Data

\begin{tabular}{|c|c|c|c|}
\hline Variable 1 & Variable 2 & Pearson r $(95 \% \mathrm{CI})$ & $P$ \\
\hline PIP & $\mathrm{V}_{\mathrm{T}}$ & $-0.037(-0.109$ to 0.035$)$ & .31 \\
\hline $\mathrm{P}_{\mathrm{ETCO}_{2}}$ & $\mathrm{~V}_{\mathrm{T}}$ & $-0.216(-0.284$ to -0.146$)$ & $<.001$ \\
\hline $\begin{array}{l}\text { Modified driving } \\
\text { pressure } \\
\text { (PIP - PEEP) }\end{array}$ & $\mathrm{V}_{\mathrm{T}}$ & $-0.012(-0.085$ to 0.06$)$ & .74 \\
\hline $\begin{array}{l}\text { Modified driving } \\
\text { pressure } \\
\text { (PIP - PEEP) }\end{array}$ & $\mathrm{V}_{\mathrm{T}} / \mathrm{IBW}$ & $0.144(0.073-0.214)$ & $<.001$ \\
\hline $\mathrm{P}_{\mathrm{ETCO}_{2}}$ & $\mathrm{~V}_{\mathrm{T}} / \mathrm{IBW}$ & $-0.363(-0.424$ to -0.298$)$ & $<.001$ \\
\hline PIP & $\mathrm{V}_{\mathrm{T}} / \mathrm{IBW}$ & $0.112(0.04-0.183$ & .002 \\
\hline \multicolumn{4}{|c|}{$\begin{array}{l}\mathrm{PIP}=\text { peak inspiratory pressure } \\
\mathrm{V}_{\mathrm{T}}=\text { tidal volume } \\
\mathrm{P}_{\mathrm{ETCO}}=\text { = end-tidal carbon dioxide } \\
\mathrm{IBW}=\text { ideal body weight }\end{array}$} \\
\hline
\end{tabular}

Anesthesiologists physical status, emergent surgery, history of congestive heart failure and COPD, and duration of surgery, the only variable that remained statistically significant in the multivariate analysis was laparoscopic surgery. Postoperative pulmonary complications occurred in $18.6 \%$ of subjects undergoing open abdominal procedures compared with $4.2 \%$ in those having laparoscopic surgery (odds ratio 0.07, 95\% CI 0.01-0.55; $P=.01$ ).

Patients who are morbidly obese can present a significant challenge for intraoperative ventilation. Decreased lung volumes $^{26,27}$ and decreased respiratory compliance ${ }^{28}$ can lead to hypercapnia, hypoxia, and high inspiratory pressures. In addition, laparoscopic surgery has been conceived to promote atelectasis by displacing the diaphragm cephalad and decreasing pulmonary compliance. In fact, higher levels of PEEP are required to maintain a neutral transpulmonary pressure..$^{29}$ If laparoscopic surgery remains a protective risk factor in prospective studies for patients who are morbidly obese, it would suggest that the pulmonary benefits of laparoscopic abdominal procedures (compared with open procedures) outweigh the intraoperative challenges that may arise from the increased intra-abdominal pressure.

Our study had several strengths. We used the electronic system to include the largest sample to date in a study that concerned perioperative protective ventilation in the patients who were morbidly obese. Our outcomes were based on diseases and diagnoses for which they were clinically relevant. Moreover, the data collection for intraoperative ventilatory parameters was accurate because it is electronically and prospectively generated and filtered for erroneous data. 


\section{Postoperative PUlmonary Complications AND OBesity}

We acknowledge several limitations in our study. The retrospective nature of our cohort had an inherent risk for selection bias, and the accuracy of the postoperative events was limited by reporting. Although postoperative events remain close to those of the general population, these are underestimated when considering the higher overall rates in patients who are obese. ${ }^{12}$ In addition, only $17.8 \%$ of the subjects received low $\mathrm{V}_{\mathrm{T}}$. This limited our ability to determine other independent predictors, such as $\mathrm{V}_{\mathrm{T}}$ or peak pressure.

The clinical outcomes are based on International Classification of Diseases code diagnoses and not on events determined by clinical criteria. For certain complications, such as atelectasis, pneumonia, or bronchitis, a diagnosis may only be generated in the medical record when it needs to be addressed as a clinical problem or may be suspected and recorded in the record but not confirmed. In addition, routine imaging may not be performed to confirm the absence of a complication. Overall, we suspect the rate of events was underestimated with this approach. Although clinically modifiable as an independent variable, $V_{T}$ may be protective because of the resultant effect on inspiratory pressures. In fact, the only intraoperative ventilatory parameter in the LAS VEGAS study that conferred a higher risk of complications was peak pressure. ${ }^{18}$ Overall, the evidence is limited in evaluating $\mathrm{V}_{\mathrm{T}}$ independently because the studies investigated mainly bundled interventions ${ }^{6}$ or adjusting $\mathrm{V}_{\mathrm{T}}$ in function of the resultant inspiratory pressures. ${ }^{16}$

\section{Conclusions}

$\mathrm{V}_{\mathrm{T}}$ was not correlated to an increased frequency or risk of postoperative pulmonary complications in the subjects who were morbidly obese and undergoing prolonged abdominal surgery. The optimum ventilation strategy for this population is still unclear. Prospective trials that compare the effect of adherence with a protective ventilation bundle to the current practice in patients who are morbidly obese are, therefore, required. Alternatively, other ventilation targets, such as peak pressure, individualized PEEP titration, and transpulmonary pressures, might clarify the actual role of $\mathrm{V}_{\mathrm{T}}$ in pulmonary complications. We propose that the outcomes of future studies should continue to be clinical and weigh the severity of complications, ultimately influencing clinical practice.

\section{ACKNOWLEDGMENTS}

We thank David Boy for the electronic data collection and his input with regard to the use of Structured Query Language in this study.

\section{REFERENCES}

1. Serpa Neto A, Hemmes SN, Barbas CS, Beiderlinden M, Biehl M, Binnekade JM, et al; PROVE Network Investigators. Protective versus conventional ventilation for surgery: a systematic review and individual patient data meta-analysis. Anesthesiology 2015;123(1):66-78.

2. Tao T, Bo L, Chen F, Xie Q, Zou Y, Hu B, et al. Effect of protective ventilation on postoperative pulmonary complications in patients undergoing general anaesthesia: a meta-analysis of randomised controlled trials. BMJ Open 2014;4(6):e005208-e005208.

3. Ladha K, Vidal Melo MF, McLean DJ, Wanderer JP, Grabitz SD, Kurth T, Eikermann M. Intraoperative protective mechanical ventilation and risk of postoperative respiratory complications: hospital based registry study. BMJ 2015;351:h3646.

4. Futier E, Constantin JM, Paugam-Burtz C, Pascal J, Eurin M, Neuschwander A, et al; IMPROVE Study Group. A trial of intraoperative low-tidal-volume ventilation in abdominal surgery. N Engl J Med 2013;369(5):428-437.

5. PROVE Network Investigators for the Clinical Trial Network of the European Society of Anaesthesiology; Hemmes SN, Gama de Abreu M, Pelosi P, Schultz MJ. High versus low positive end-expiratory pressure during general anaesthesia for open abdominal surgery (PROVHILO trial): a multicentre randomised controlled trial. Lancet 2014;384(9942):495-503.

6. Guldner A, Kiss T, Serpa Neto A, Hemmes SN, Canet J, Spieth PM, et al. Intraoperative protective mechanical ventilation for prevention of postoperative pulmonary complications: a comprehensive review of the role of tidal volume, positive end-expiratory pressure, and lung recruitment maneuvers. Anesthesiology 2015;123(3):692-713.

7. Josephs SA, Lemmink GA, Strong JA, Barry CL, Hurford WE. Improving adherence to intraoperative lung-protective ventilation strategies at a university medical center. Anesth Analg 2017;126 (1): $150-160$

8. Jaber S, Coisel Y, Chanques G, Futier E, Constantin J-M, Michelet P, et al. A multicentre observational study of intra-operative ventilatory management during general anaesthesia: tidal volumes and relation to body weight. Anaesthesia 2012;67(9):999-1008.

9. Fernandez-Bustamante A, Hashimoto S, Serpa Neto A, Moine P, Vidal Melo MF, Repine JE. Perioperative lung protective ventilation in obese patients. BMC Anesthesiol 2015;15:56.

10. de Jong MAC, Ladha KS, Vidal Melo MF, Staehr-Rye AK, Bittner EA, Kurth T, et al. Differential effects of intraoperative positive endexpiratory pressure (PEEP) on respiratory outcome in major abdominal surgery versus craniotomy. Ann Surg 2016;264(2):362-369.

11. Canet J, Gallart L, Gomar C, Paluzie G, Vallès J, Castillo J, et al; ARISCAT Group. Prediction of postoperative pulmonary complications in a population-based surgical cohort. Anesthesiology 2010;113 (6):1338-1350.

12. Mazo V, Sabaté S, Canet J, Gallart L, de Abreu MG, Belda J, et al. Prospective external validation of a predictive score for postoperative pulmonary complications. Anesthesiology 2014;121(2):219-231.

13. Mayhew D, Mendonca V, Murthy BVS. A review of ASA physical status - historical perspectives and modern developments. Anaesthesia 2019;74(3):373-379.

14. Fernandez-Bustamante A, Frendl G, Sprung J, Kor DJ, Subramaniam B, Martinez Ruiz R, et al. Postoperative pulmonary complications. Early mortality, and hospital stay following noncardiothoracic surgery: a multicenter study by the perioperative by the Research Network Investigators. JAMA Surg 2017;152(2):157-166.

15. Lakshminarasimhachar A, Smetana GW. Preoperative evaluation: estimation of pulmonary risk. Anesthesiol Clin 2016;34(1):71-88.

16. Acute Respiratory Distress Syndrome Network; Brower RG, Matthay MA, Morris A, Schoenfeld D, Thompson BT, Wheeler A. Ventilation with lower tidal volumes as compared with traditional tidal volumes for acute lung injury and the acute respiratory distress syndrome. $\mathrm{N}$ Engl J Med 2000;342(18):1301-1308.

17. Ball L, Hemmes SNT, Serpa Neto A, Bluth T, Canet J, Hiesmayr M, et al; LAS VEGAS Investigators; PROVE Network; Clinical Trial 


\section{Postoperative Pulmonary Complications ANd OBesity}

Network of the European Society of Anaesthesiology. Intraoperative ventilation settings and their associations with postoperative pulmonary complications in obese patients. Br J Anaesth 2018;121(4):899908.

18. LAS VEGAS investigators. Epidemiology, practice of ventilation and outcome for patients at increased risk of postoperative pulmonary complications: LAS VEGAS - an observational study in 29 countries. Eur J Anaesthesiol 2017;34(8):492-507.

19. Lukannek C, Shaefi S, Platzbecker K, Raub D, Santer P, Nabel S, et al. The development and validation of the Score for the Prediction of Postoperative Respiratory Complications (SPORC-2) to predict the requirement for early postoperative tracheal re-intubation: a hospital registry study. Anaesthesia 2019;74(9):1165-1174.

20. De Oliveira GS Jr, McCarthy RJ, Davignon K, Chen H, Panaro H, Cioffi WG. Predictors of 30-day pulmonary complications after outpatient surgery: relative importance of body mass index weight classifications in risk assessment. J Am Coll Surg 2017;225(2):312-323.e7.

21. Opperer M, Cozowicz C, Bugada D, Mokhlesi B, Kaw R, Auckley $\mathrm{D}$, et al. Does obstructive sleep apnea influence perioperative outcome? A qualitative systematic review for the society of anesthesia and sleep medicine task force on preoperative preparation of patients with sleep-disordered breathing. Anesth Analg 2016;122(5):13211334.

22. Reinius H, Jonsson L, Gustafsson S, Sundbom M, Duvernoy O, Pelosi $\mathrm{P}$, et al. Prevention of atelectasis in morbidly obese patients during general anesthesia and paralysis: a computerized tomography study. Anesthesiology 2009;111(5):979-987.
23. Whalen FX, Gajic O, Thompson GB, Kendrick ML, Que FL, Williams BA, et al. The effects of the alveolar recruitment maneuver and positive end-expiratory pressure on arterial oxygenation during laparoscopic bariatric surgery. Anesth Analg 2006;102(1):298-305.

24. Talab HF, Zabani IA, Abdelrahman HS, Bukhari WL, Mamoun I, Ashour MA, et al. Intraoperative ventilatory strategies for prevention of pulmonary atelectasis in obese patients undergoing laparoscopic bariatric surgery. Anesth Analg 2009;109(5):1511-1516.

25. Writing Committee for the PROBESE Collaborative Group of the PROtective VEntilation Network (PROVEnet) for the Clinical Trial Network of the European Society of Anaesthesiology; Bluth T, Serpa Neto A, Schultz MJ, Pelosi P, Gama de Abreu M, PROBESE Collaborative Group, , et al. Effect of intraoperative high positive end-expiratory pressure (PEEP) with recruitment maneuvers vs low PEEP on postoperative pulmonary complications in obese patients: a randomized clinical trial. JAMA 2019;321(23):2292-2305.

26. Littleton SW, Tulaimat A. The effects of obesity on lung volumes and oxygenation. Respir Med 2017;124:15-20.

27. Mehari A, Afreen S, Ngwa J, Setse R, Thomas AN, Poddar V, et al. Obesity and pulmonary function in African Americans. PLoS One 2015;10(10):e0140610.

28. Behazin N, Jones SB, Cohen RI, Loring SH. Respiratory restriction and elevated pleural and esophageal pressures in morbid obesity. $\mathrm{J}$ Appl Physiol (1985) 2010;108(1):212-218.

29. Eichler L, Truskowska K, Dupree A, Busch P, Goetz AE, Zollner C. Intraoperative ventilation of morbidly obese patients guided by transpulmonary pressure. Obes Surg 2018;28(1):122-129. 